\title{
A Faceted Taxonomy for Rating Student Bibliographies in an Online Information Literacy Game
}

\section{Chris Leeder, Karen Markey, and Elizabeth Yakel}

This study measured the quality of student bibliographies through creation of a faceted taxonomy flexible and fine-grained enough to encompass the variety of online sources cited by today's students. The taxonomy was developed via interviews with faculty, iterative refinement of categories and scoring, and testing on example student bibliographies. It was then applied to evaluate the final bibliographies created in BiblioBouts, an online social game created to teach undergraduates information literacy skills. The scores of players and nonplayers were compared and showed a positive impact from the game. Findings of the evaluations of these student bibliographies are discussed.

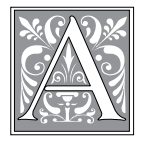

s online searching of digital libraries becomes the primary avenue for student research and digital information sources proliferate, Information Literacy (IL) competence has become fundamentally important for incoming college students. Important IL skills include: mastering the ability to effectively search for information, critically evaluating how evidence is presented in information sources and properly integrating them into research assignments. However, many undergraduate students do not receive this crucial education when they enter college; the majority of institutions that provide firstyear experience programs do not require any information literacy content. ${ }^{1}$ Aca- demic librarians attempt to reach as many students as they can through a wide range of venues, such as for-credit courses, inclass (often "one shot") training sessions, walk-up assistance at reference desks, and online chat. Yet these outreach methods still reach only a fraction of the student population.

The BiblioBouts project uses social gaming to teach information literacy skills to undergraduates alongside their regular coursework. The game is an online accompaniment to the traditional in-class research paper assignment and engages students in each stage of the research process through competitive gameplay. BiblioBouts introduces students to a step-by-step research process in which

Chris Leeder is a Doctoral Student, Karen Markey is a Professor, and Elizabeth Yakel is a Professor in the School of Information at the University of Michigan; e-mail: cleeder@umich.edu, ylime@umich.edu, yakel@umich.edu. The researchers wish to thank the members of the BiblioBouts team: Victor Rosenberg, Beth St. Jean, Fritz Swanson, Brian Jennings, Greg Peters, Andrew Calvetti, and three university faculty members who participated in the study. Special thanks to the Institute for Library and Museum Studies for their support of this project through a National Leadership Grant. (c) Chris Leeder, Karen Markey, and Elizabeth Yakel 
each minigame or "bout" embodies a discrete stage of research, walking students through the steps of searching for and collecting sources, evaluating sources for credibility and relevance, narrowing down the scope of the research topic, selecting the best sources for that topic, and creating a bibliography of quality sources that support the research topic. (For more information on BiblioBouts, see the project Web site at: http://bibliobouts. si.umich.edu/index.html.)

To evaluate the game's effectiveness in achieving its goals, a measurement of learning outcomes needed to be developed. Since the game's final result is a research paper bibliography, the researchers chose to measure the effectiveness of the game by measuring the difference in quality of student bibliographies between players (treatment group) and nonplayers (control group). A standardized assessment tool was designed to quantitatively assess differences in the quality of the bibliographies produced by students in the same pilot class who did, and did not, play BiblioBouts. Since the majority of the sources cited by players were online, the rating tool needed to be multifaceted, fine-grained, and format-neutral. This study outlines the development of this tool for assessing quality of student bibliographies to measure the game's impact.

\section{Research Questions}

Three fundamental research questions motivated this study:

1. How does one operationalize "quality" of student bibliographies?

2. Can a standardized assessment tool be developed that is flexible enough to encompass the variety of online sources cited by today's students?

3. Does playing the BiblioBouts game improve the quality of student bibliographies?

These questions were addressed through the use of both qualitative and quantitative research techniques during the process of pilot testing and refinement of the game and were measured through the development of a faceted taxonomy for classifying and rating online sources.

This research topic is important because developing a standardized bibliographic assessment tool that is effective in measuring the quality of online citations is potentially useful to a wide audience of librarians, information literacy instructors, and faculty members. In addition, this measurement standard would contribute to the development of the BiblioBouts project and help promote the effectiveness of a new information literacy skills development tool. Thus, this research will be important for librarians, information literacy instructors, and any faculty who assign undergraduate student research papers.

\section{Literature Review}

The literature of information literacy assessment is large. A recent overview of 91 case studies of information literacy assessment found that citation analysis of bibliographies was the second most common technique $(17 \%)$, behind multiple choice questionnaires (34\%) (Walsh, 2009). However, even within the bibliographic analysis examples, the purpose of the information literacy assessment varied from the overall counting of resource types to a specific focus on Web-based sources. The standards and methodologies used in each of these case studies were developed and used by individual librarians with specific needs and interests. Walsh cites concern over "the lack of rigorously designed assessment of information literacy in higher education" 2 as demonstrated by the lack of reliability and validity measures in many of these case studies.

Citation analysis of student bibliographies has been frequently used by librarians as a quantified assessment tool. Citation analysis can measure what sources students are actually using and offers "a flexible, non-invasive, time-efficient assessment forum for the documentation of student library use." ${ }^{3}$ However, while 
review of the literature reveals that librarians have frequently employed citation analysis as an assessment tool, it also shows that they have used varying sets of criteria with varying assessment goals in employing this technique. Criteria frequently used include currency, relevance, correctness of citation format, quality, and scholarliness. However, the definitions of terms are not standard and vary from study to study, as do the methods of measurement. Currency could be determined by a set number of years from publication date or with a more subjective assessment of current issues in the field. Relevance is notoriously difficult to define ${ }^{4}$ and a variety of definitions and criteria are employed in the literature, each of which

\begin{tabular}{|c|c|c|c|c|c|}
\hline \multicolumn{6}{|c|}{$\begin{array}{c}\text { TABLE } 1 \\
\text { Reviewed Bibliography Evaluation Criteria }\end{array}$} \\
\hline Author(s) & Variety & Currency & Relevance & Correctness & Scholarliness \\
\hline Kirk 1971 & $\mathrm{X}$ & & $\mathrm{X}$ & & $\mathrm{X}$ \\
\hline Dykeman \& King 1983 & $\mathrm{X}$ & & & & $\mathrm{X}$ \\
\hline Gratch 1985 & $\mathrm{X}$ & $\mathrm{X}$ & $\mathrm{X}$ & $\mathrm{X}$ & \\
\hline Kohl \& Wilson 1986 & & $\mathrm{X}$ & & & $\mathrm{X}$ \\
\hline St. Clair \& Magrill 1990 & & & & $\mathrm{X}$ & \\
\hline Young \& Ackerson 1995 & & $\mathrm{X}$ & & & $\mathrm{X}$ \\
\hline Malone \& Videon 1997 & & & & $\mathrm{X}$ & \\
\hline \multicolumn{6}{|l|}{ Hovde 2000} \\
\hline Davis \& Cohen 2001 & & & & $\mathrm{X}$ & $\mathrm{X}$ \\
\hline Oppenheim \& Smith 2001 & & $\mathrm{X}$ & & & \\
\hline Davis 2002 & & & & $\mathrm{X}$ & \\
\hline Heller-Ross 2002 & & $\mathrm{X}$ & & & \\
\hline Hinchcliffe, et al. 2002 & & $X$ & & & $X$ \\
\hline Emmons \& Martin 2002 & & $X$ & $X$ & & \\
\hline Beile 2003 & & $\mathrm{X}$ & & $\mathrm{X}$ & $\mathrm{X}$ \\
\hline Robinson \& Schlegel 2004 & & & & & $\mathrm{X}$ \\
\hline \multicolumn{6}{|l|}{ Ursin et al. 2004} \\
\hline \multicolumn{6}{|l|}{ Leiding 2005} \\
\hline Long \& Shrikhande 2005 & $\mathrm{X}$ & & & $\mathrm{X}$ & $\mathrm{X}$ \\
\hline Mohler 2005 & & & & & $\mathrm{X}$ \\
\hline Middleton 2005 & & & & & $\mathrm{X}$ \\
\hline \multicolumn{6}{|l|}{ Carlson 2006} \\
\hline Clarke \& Oppenheim 2006 & & $\mathrm{X}$ & & $\mathrm{X}$ & \\
\hline Knight 2006 & & & & $\mathrm{X}$ & $\mathrm{X}$ \\
\hline Tuñón \& Brydges 2006 & & $\mathrm{X}$ & $\mathrm{X}$ & & $\mathrm{X}$ \\
\hline Wang 2006 & & & & $\mathrm{X}$ & $\mathrm{X}$ \\
\hline Yu 2006 & $\mathrm{X}$ & & & $\mathrm{X}$ & \\
\hline Edzan 2008 & & $\mathrm{X}$ & & $\mathrm{X}$ & $\mathrm{X}$ \\
\hline Knight-Davis \& Sung 2008 & & $X$ & & & $\mathrm{X}$ \\
\hline
\end{tabular}


requires careful evaluation. Correctness of citation format clearly relies upon the specific format (if any) required by the instructor and also requires careful individual inspection of each citation. Quality of citations is also difficult to quantify, given the many factors that contribute to such a judgment. ${ }^{5}$

This review classifies the main criteria used in the reviewed literature to assess student bibliographies. Table 1 lists the studies reviewed herein in chronological order, showing the criteria categories along the top row, with Xs indicating the authors who discussed each criterion. One method not included in this review is numeric counts of the total number of citations and the total number of cited sources by type (such as book, journal, magazine, or Web site). While these techniques are employed in almost all of the studies reviewed herein, because they are strictly numeric and do not involve evaluation criteria they are not included in this review.

Influential early studies by Kirk, ${ }^{6}$ Dykeman \& King, ${ }^{7}$ Gratch, ${ }^{8}$ Kohl \& Wilson, ${ }^{9}$ and Young \& Ackerson ${ }^{10}$ set the groundwork for the evaluation of bibliographic instruction through rating bibliographies. Kirk scored bibliographies according to criteria for variety, relevance, and scholarliness, then compared resulting scores from two types of bibliographic instruction. Dykeman \& King used a similar methodology, including other criteria such as writing, organization, and content and comparing the results between a treatment group that received bibliographic instruction and a control group. Gratch reviewed four research studies, including Kirk and Dykeman \& King and pointed out that, while a direct cause-and-effect relationship between instruction and bibliography quality is often assumed, many intervening variables may also affect the outcome. Kohl \& Wilson followed the same methodology as Kirk and Dykeman \& King but used criteria of appropriateness, currency, and quality. Young \& Ackerson used Kohl \&
Wilson's criteria in a similar study and proposed suggestions for increasing the effectiveness of evaluation criteria used in evaluating bibliographic instruction.

Another common use of citation analysis by librarians is as a measurement tool of library ownership of materials ${ }^{11}$ and for collection development. ${ }^{12}$ In this model, student citations are counted and used as a measurement of which journals and other library materials are most and least used by students, and the results are used to guide purchase or discontinuation of materials. Other studies focus on a particular disciplinary area and analyze the usage of journals in that field (such as education, ${ }^{13}$ mathematics, ${ }^{14}$ composition studies, ${ }^{15}$ agriculture and biology, ${ }^{16}$ chemistry, ${ }^{17}$ or workforce development ${ }^{18}$ ). These studies help librarians analyze student usage patterns and assist library administrators in making collection and budgetary decisions.

There are numerous citation analysis case studies in the library literature. These studies have a variety of specific evaluation goals: determining which library databases were used by students to access materials, ${ }^{19}$ frequency of use of online sources, ${ }^{20}$ persistence of URLs cited, ${ }^{21}$ citation of electronic journals, ${ }^{22}$ and use of items in a subject-specific resource guide. ${ }^{23}$ These studies provide precise detail on specific student behaviors in regard to library research and resource usage. Case studies have also demonstrated the positive impact on the quality of student bibliographies of instructor guidelines for citations, ${ }^{24}$ inquiry-based library instruction, ${ }^{25}$ and a credit-bearing library instruction course. ${ }^{26}$

Multiple factors that may influence student bibliography outcomes have been studied, including comparisons of citation practices by student class year, discipline and source types; ${ }^{27}$ between students living on-campus and off-campus; ${ }^{28}$ between class year and number and variety of sources cited; ${ }^{29}$ and between student work at traditional vs. nontraditional institutions $^{30}$ and multiple campuses. ${ }^{31}$ Studies 
have also investigated any correlation between number of citations and word count of the paper ${ }^{32}$ and between number of citations and final grade..$^{33}$

Some studies developed customized assessment rubrics, often based on the Association of College and Research Libraries (ACRL) Information Literacy Competency Standards for Higher Education (www.ala.org/ala/mgrps/divs/acrl/ standards/informationliteracycompetency.cfm). Rubrics establish criteria for judging performance, identify a range in the quality of performance, determine a scoring standard, and label levels of quality. ${ }^{34}$ Tuñón discusses the frequent use of rubrics as an assessment tool to document library research skills and notes that "using rubrics in conjunction with citation analysis is not a new concept for librarians." ${ }^{35}$ Dykeman and King used a scoring guide for citations, ${ }^{36}$ while Long and Shrikhande used an information literacy grading scale. ${ }^{37}$ One drawback of these rubrics, however, is that they often rely on individual assessments by instructors of attributes such as "variety," "utilization," and "quality of resources," which lack an objective measurement criteria. Rubrics based on the ACRL's standards rely on interpretation of the IL broad learning goals that also lack an objective standard for measurement. Emmett and Emde used a "backward design method" 38 to map specific learning objectives onto the ACRL standards; precisely how these questions were mapped is left unclear, however.

The quality of bibliographies has been used as a criterion in citation analysis studies by Davis and Cohen, ${ }^{39}$ Beile, Boote \& Killingsworth, ${ }^{40}$ Edzan, ${ }^{41}$ and others. In these studies, "quality" is generally defined as a measure of the student's use of scholarly sources, which is obtained by grading each citation against a set of standard scoring criteria. For example, Tuñón and Brydges's rubric scored a citation on five criteria (breadth of resources, depth of understanding, level of scholarliness or "quality," currency, and relevance) on a scale of 1 to 4 points. ${ }^{42}$
Middleton developed a rating system in which these types of measurements are used to generate a "scholarly index" (SI) to quantify the proportion of scholarly vs. nonscholarly sources used in the bibliography..$^{43}$ One limitation of this system is the broad binary choice of "scholarly vs. nonscholarly," which does not leave much room for more fine-grained analysis of the level of scholarliness in different types of sources. However, the quantitative rating scale of Middleton's "scholarly index" was one of the initial inspirations for the taxonomy system ultimately developed for this study.

While assessment of the scholarliness of sources is an important element of overall quality of sources in a bibliography, it is not the only criterion. Other important factors that can be considered in assessing quality are currency of sources (Heller-Ross, ${ }^{44}$ Hinchcliffe et al., ${ }^{45}$ Oppenheim and Smith, ${ }^{46}$ Young and Ackerson ${ }^{47}$ ), relevance of sources to the research topic $\left(\right.$ Gratch $^{48}$ Kohl and Wilson ${ }^{49}$ ), and correctness or completeness of citation style (Malone and Videon, ${ }^{50}$ Hinchcliffe et al., ${ }^{51}$ Mohler, ${ }^{52}$ Wang $\left.^{53}\right)$. Each of these assessment techniques requires substantial time investment by the researcher. Emmett \& Emde note "the need to make assessment projects manageable given the time constraints of most library instructors, ${ }^{154}$ and this is certainly a reasonable concern for researchers when considering the adoption of a citation analysis methodology.

The variety and diversity of the methodologies used to measure information literacy skills reviewed, however, suggests a lack of agreed-upon standards for assessing student bibliographies, rooted in the divergent goals and methodologies employed. Many of these studies measure certain specific criteria, but most do not measure the overall quality of student work as exhibited in the bibliography; nor do they apply an explicit coding and rating system. Thus, while the studies reviewed informed the development of the taxonomy system, the individual methodologies reviewed above were not 
directly adopted for this study because of the unique qualities and diversity of online sources used by student researchers today. It is difficult and potentially inaccurate to judge online sources by only one binary choice (such as "scholarly vs. nonscholarly"). There are gradations between an online magazine and an online journal, for instance, and sources such as blogs, forums, and digital repositories do not fit neatly into the traditional bibliographic format choices. Simply categorizing an online site as a Web page, as many of the above studies have done, does not provide enough information to judge its quality as an information source. Multiple other criteria must also be considered.

The faceted classification methodology attempts to integrate multiple criteria into one standard assessment tool. Cool \& Belkin developed a classification system for categorizing information-seeking behaviors, built on four facets with "dichotomous values" 55 that could be combined across multiple contexts to explicitly characterize a wide variety of related types. Crowston \& Kwasnik created a faceted classification system for categorizing online genres, describing it as a "multidimensional description" that can "view the object from all its angles." ${ }^{\prime 56}$ Neither of these examples, however, applied the faceted taxonomy model to citation analysis. The faceted classification system also allows for explicit scoring of each facet, as well as combining these individual scores into a comprehensive citation score that can be compared against others on a single scale. Along with this capacity to assess multiple source formats and criteria, the faceted taxonomy can also accommodate new and emerging genres and phenomena. This approach to bibliographic classification seems particularly appropriate to the Internet era, with its blurring of forms and genres. The faceted taxonomy system does not rely on traditional hierarchies with a single organizing principle, which may not be useful or appropriate for all cases but is open and adaptable to multiple variables and criteria.

\section{Methodology}

Based on the literature review, the researchers determined that a singlecategory rating criteria (such as scholarly or nonscholarly) was not sufficient to capture enough detail about the sources used by today's students. The wide range of information formats and content available through online research calls for the development of a more fine-grained rating system that describes the multiple facets of these information sources. While in the early days of the Internet, coding a source as "a Web page" may have been appropriate, today this is not informative. A Web page can contain anything from a scholarly journal database to an individual's blog; it is fundamentally important to differentiate between the two.

These factors led the researchers to create a rating taxonomy that is "format neutral." A scholarly journal article in print is effectively equivalent to a scholarly journal article online, and both should be considered functionally identical. The physical nature of the source (print or online) does not tell us much about its content and is not a useful measure of the quality of the source. While rating sources simply as "books" or "journals" may be useful for collection development purposes, it only captures one aspect of an information source. A thorough rating system should also capture the type of content contained in the source, the authorship, the editorial process employed in creating the information, and the purpose of the publication. For the present study, a faceted taxonomy was adopted because it can combine multiple criteria of classification (such as type of source, type of content, or type of authorship) into a single classification of a citation. Thus, the goal of this study was to measure the overall quality of student work as exhibited in the bibliography and to apply an explicit coding and rating system to quantify the results.

The faceted taxonomy was developed through a three-stage process. In the first step of developing the taxonomy, 
an initial draft taxonomy was developed and refined iteratively by the researchers. Second, the faculty instructors of three BiblioBouts pilot classes were interviewed regarding their criteria for assessing bibliographies. Third, a scoring scale for the taxonomy was developed by the researchers and reviewed by the faculty members, who independently scored the items in the taxonomy, and the four sets of scores (three faculty and one researcher) were analyzed to establish inter-rater reliability. Fourth, the taxonomy and scoring system were applied to bibliographies produced by students in the pilot class, and the scoring results were compared between students who played BiblioBouts and those who did not.

\section{Faculty Interviews}

To gain a better understanding of how bibliographies are integrated with research assignments, we interviewed the faculty in charge of each pilot class regarding their class learning objectives, research paper requirements, and grading criteria. We asked the following interview questions: "When you assign papers, what oral and written instructions do you give to students, e.g., length, format, content, grading criteria? What rules and guidelines do you provide that could help students to select literature for their papers? What do you tell students about your expectations for their bibliographic entries, e.g., number, selection, format, variety of such entries, their scholarly nature? What is an average bibliographic entry, an exemplary entry, and a poor entry?"

Some interesting findings emerged from these interviews. Two instructors indicated that theirs was "not a writing class" and that they did not specifically grade citations. One commented "it is not our task to teach writing in these classes," and another stated "I don't dig back into the sources, typically there's not time." These instructors reported that they grade papers mainly on the argument and the use of evidence in the papers. Grading was based on argumentation and understand- ing of concepts but did not incorporate an evaluation of the citations, except as a numerical requirement. The instructors also reported that they generally do not provide specific guidance on what types of sources to cite or what basis students should use for evaluating sources.

These results suggest that instructors may view citation practices as a purely "writing" skill distinct from the content of a class and its learning objectives and not in the purview of their teaching expertise. They seem to see the quality of a student's writing and citing as being the domain of "writing intensive" classes, rather than incorporated as part of the research paper assignments in their courses. In addition, the instructors commented that students did not seem to have much, if any, library research experience before entering these classes and may not be familiar with what elements constitute a quality research bibliography.

Thus, the BiblioBouts game holds the promise of integrating critical information literacy skills into the classroom setting in conjunction with actual assignments, so that students see the utility of the skills and can apply them to their practical, real-world lives. Rather than relying on a segregated, formal instruction session on information literacy, which may seem abstract to students and not directly related to their coursework, the necessary skills are learned during game play in a useful and practical context related directly to their current assignment. Since these faculty do not currently grade citations or bibliographies, BiblioBouts offers an additional learning opportunity for students as well as a concrete assessment tool for instructors.

\section{Draft Taxonomy}

To develop the taxonomy, the researchers developed an initial list of possible facets, each with a basic set of broad subtypes. The five main facets were: Information Format, Literary Content, Author Identity, Editorial Process, and Publication Purpose. Information Format was defined 
as the basic classification of the type of document, such as newspaper or scholarly journal. The Literary Content was separated from the Information Format to explicitly characterize the informational nature of the material cited, apart from the generic format it is contained in: for instance, a newspaper may contain editorials or essays, and a scholarly journal may contain literature reviews or research articles. As with all faceted taxonomies, the categories are not hierarchical but combinatory, as each facet is independent and can be combined with any other facet to capture the unique characteristics of any individual source. No one facet was considered the primary and overriding factor to be used in evaluation.

After review and discussion, the team developed the list of subtypes of Information Format by consulting the categories of "document type" employed by Ulrich's Periodical Directory (www.ulrichsweb. com), a widely recognized authority on periodical resources. Based on Ulrich's definitions of "newspaper," "magazine," "journal," and "monographic series," and their classifications of "consumer" and "trade" versions, twenty-two subtypes of the Information Format facet were enumerated. Other types of information sources used by college students, such as encyclopedias, reports, and conference proceedings, were also added, as well as additional formats applicable to the online environment, including blog and digital repository.

The development of this taxonomy was an iterative process. As the initial draft was developed, it was applied to sample citations from student bibliographies. When citations were discovered that could not be classified by the draft taxonomy, new elements were added. The taxonomy was continually revised through this process. Initially, an "intended audience" facet was considered, but it was ultimately discarded because the researchers felt that too much subjective judgment was required to apply it to many online sources. Since intended audience is rarely described explicitly and one source may have many intended audiences, this facet was found not to be useful and was removed. This refinement process continued until the researchers felt that the taxonomy was robust enough to encompass the variety of types of sources found on the sample bibliographies. The researchers consulted with faculty colleagues, who reviewed the list and gave feedback, and the taxonomy was finalized.

\section{Taxonomy Scoring}

Once an initial taxonomy was developed, scores were applied by the researchers to each category, based on the researcher's judgment of how useful and appropriate each type of element would be to an undergraduate student researching sources for a class assignment. Values for the scores were based on the reliability, relevance, and scholarliness of each assessed item, as well as the likelihood of the item being vetted by an objective reviewer. Ulrich's was consulted for their classification of refereed or peer-reviewed status. A scale of 1 to 4 was used, with 1 being low and 4 being high. The score for each of the five facets would be combined to create a total score for each citation. Using this system, the most highly rated citation could earn a total of 20 points, while the lowest rated citation would earn 5 points.

First, the researchers developed an initial numeric rating score for each of the taxonomy categories on a scale of $1-4$,

\begin{tabular}{|c|c|c|}
\hline \multicolumn{3}{|c|}{$\begin{array}{c}\text { TABLE } 2 \\
\text { Cohen's Kappa Scores for Paired } \\
\text { Raters }\end{array}$} \\
\hline $\begin{array}{l}\text { Paired } \\
\text { Raters }\end{array}$ & $\begin{array}{l}\text { Kappa } \\
\text { Scores }\end{array}$ & $\begin{array}{l}\text { 95\% Confidence } \\
\text { Interval }\end{array}$ \\
\hline $1-2$ & .4808 & $0.3148-0.6468$ \\
\hline $1-3$ & .2012 & $0.0515-0.3508$ \\
\hline $1-4$ & .3553 & $0.1877-0.5229$ \\
\hline $2-3$ & .0374 & $-0.1084-0.1832$ \\
\hline $2-4$ & .3648 & $0.1968-0.5328$ \\
\hline $3-4$ & .1131 & $-0.0281-0.2543$ \\
\hline
\end{tabular}


1 being low and 4 being high. Then, the faculty members for each of the three pilot classes were asked to independently score the taxonomy to verify the generalizability of the scoring. Faculty were provided with the draft taxonomy and asked: "For each of the elements listed under the facets below, please circle your rating of the quality of the element on a scale from $1-4$, based on how you would evaluate it as a component of a cited source in a college undergraduate research paper in your class." The scores from all raters were subjected to statistical analysis to

\begin{tabular}{|c|c|c|c|c|c|}
\hline \multicolumn{6}{|c|}{$\begin{array}{c}\text { TABLE } 3 \\
\text { Faceted Taxonomy and Scoring System }\end{array}$} \\
\hline $\begin{array}{l}\text { Facet 1: Information } \\
\text { Format }\end{array}$ & Score & $\begin{array}{l}\text { Facet 2: Literary } \\
\text { Content }\end{array}$ & Score & Facet 3: Author Identity & Score \\
\hline 1A: Blog & 1.3 & 2A: FAQ & 1.5 & 3A: Unknown Authorship & 1.0 \\
\hline $\begin{array}{l}\text { 1B: Promotional } \\
\text { Material }\end{array}$ & 1.5 & 2B: Posting & 1.5 & 3B: Layman & 1.3 \\
\hline 1C: Public Sharing Site & 2.0 & 2C: Public Relations & 1.5 & 3C: Corporate Authorship & 1.8 \\
\hline 1D: Policy Statement & 2.0 & 2D: Column & 2.0 & 3D: Professional Amateur & 2.3 \\
\hline $\begin{array}{l}\text { 1E: Consumer } \\
\text { Magazine }\end{array}$ & 2.3 & 2E: Manual & 2.0 & 3E: Applied Professional & 3.5 \\
\hline $\begin{array}{l}\text { 1F: Consumer } \\
\text { Newspaper }\end{array}$ & 2.3 & 2F: Editorial & 2.3 & $\begin{array}{l}\text { 3F: Academic } \\
\text { Professional }\end{array}$ & 4.0 \\
\hline 1G: Directory & 2.3 & 2G: Review & 2.3 & & \\
\hline 1H: Encyclopedia & 2.3 & 2H: Class Reading & 2.5 & $\begin{array}{l}\text { Facet 4: Editorial } \\
\text { Process }\end{array}$ & Score \\
\hline 1I: News Story & 2.3 & 2I: Entry & 2.5 & 4A: Self-Published & 1.3 \\
\hline $\begin{array}{l}\text { 1J: Informational } \\
\text { Video }\end{array}$ & 2.3 & 2J: Article/News & 2.5 & 4B: Vanity Press & 1.3 \\
\hline 1K: Course Material & 2.5 & 2K: Article/Essay & 2.8 & 4C: Collaborative Editing & 2.5 \\
\hline 1L: Trade Newspaper & 2.5 & 2L: Biography & 3.0 & $\begin{array}{l}\text { 4D: Moderated } \\
\text { Submissions }\end{array}$ & 2.8 \\
\hline $\begin{array}{l}\text { 1M: Institutional } \\
\text { Repository }\end{array}$ & 2.8 & $\begin{array}{l}\text { 2M: Preprint/ } \\
\text { Postprint }\end{array}$ & 3.0 & $\begin{array}{l}\text { 4E: Editor and Editorial } \\
\text { Staff }\end{array}$ & 3.5 \\
\hline 1N: Trade Magazine & 2.8 & 2N: Thesis & 3.0 & 4F: Peer-Reviewed & 4.0 \\
\hline 1O: Database & 3.0 & 2O: Working Paper & 3.0 & & \\
\hline 1P: Digital Repository & 3.0 & $\begin{array}{l}\text { 2P: Article/Lit } \\
\text { Review }\end{array}$ & 3.3 & $\begin{array}{l}\text { Facet 5: Publication } \\
\text { Purpose }\end{array}$ & Score \\
\hline 1Q: Trade Journal & 3.0 & $\begin{array}{l}\text { 2Q: Article/ } \\
\text { Research }\end{array}$ & 3.8 & 5A: Personal & 1.3 \\
\hline 1R: Report & 3.0 & $\begin{array}{l}\text { 2R: Article/ } \\
\text { Synthesis }\end{array}$ & 3.8 & 5B: Commercial & 2.0 \\
\hline $\begin{array}{l}\text { 1S: Conference } \\
\text { Proceedings }\end{array}$ & 3.5 & 2S: Dissertation & 3.8 & 5C: Nonprofit & 3.3 \\
\hline 1T: Monograph & 3.8 & 2T: Treatise & 3.8 & 5D: K-12 Education & 3.3 \\
\hline $\begin{array}{l}\text { 1U: Monographic } \\
\text { Serial }\end{array}$ & 3.8 & & & 5E: Government & 3.5 \\
\hline 1V: Scholarly Journal & 4.0 & & & 5F: Higher Education & 4.0 \\
\hline
\end{tabular}


establish inter-rater reliability. Cohen's kappa scores were calculated for each pair of raters, as well as a confidence interval at the $95 \%$ level (see table 2). While Rater 3 generally rated items slightly higher than the average, and Rater 4 generally rated slightly lower than the average, in all cases the interval does not include zero; thus, the null hypothesis is rejected. The confidence interval of the overall kappa coefficients at the $95 \%$ level was $0.1752-0.3019$. The chi-square for the kappa scores was 22.8038 with a p-value of 0.0004 , again demonstrating that the null hypothesis was rejected. In addition, Kendall's Coefficient of Concordance for the four raters produced a $\mathrm{p}$ value of 0.000 , showing significant correlation among the raters. Given this high level of correlation, the researchers felt confident in the overall generalizability of the scoring system. Table 2 shows the statistical results of this analysis.

The average score for each item among the four raters was used as the final numerical value for that element. Scores were consistently higher for scholarly, academic, and peer-reviewed sources, while scores were consistently lower for anonymous, self-published, and nonreviewed sources. For example, a scholarly journal received an average Information Format score of 4.0, while a blog received a score of 1.3. For Editorial Process, a peerreviewed source received a 4.0 score, while a self-published source received a 1.3 score. Table 3 shows the resulting averages used for scoring the taxonomy elements.

After the individual scores for each of the five facets were generated, they were combined into a total numerical score for the citation. Each citation's total score is the sum of the Information Format, Literary Content, Author Identity, Editorial Process, and Publication Purpose scores. For example, suppose two different citations were to be rated: a research article by a $\mathrm{PhD}$ in a peer-reviewed scholarly journal and an anonymous online Wikipedia entry. Table 4 shows the total scores for these two example citations.

\section{Coding of Pilot Bibliographies}

The final bibliographies from one pilottested undergraduate class were analyzed using the faceted taxonomy. The class consisted of 100 students who were assigned a research paper as part of the class requirements. The class was an entry-level introductory course crosslisted between the Schools of Information and Sociology with an assigned research topic of "Business Models for Web 2.0 Social Networking Sites \& Platforms." Students volunteered to play BiblioBouts, incentivized by receiving extra credit on

\begin{tabular}{|c|c|c|c|}
\hline \multicolumn{4}{|c|}{$\begin{array}{c}\text { TABLE } 4 \\
\text { Examples of Coded and Scored Citations }\end{array}$} \\
\hline \multicolumn{2}{|c|}{ Research article in a peer-reviewed journal } & \multicolumn{2}{|l|}{ Anonymous Wikipedia entry } \\
\hline Facet & Score & Facet & Score \\
\hline $\begin{array}{l}\text { Information format: Scholarly } \\
\text { Journal }\end{array}$ & 4.0 & Information format: Encyclopedia & 2.3 \\
\hline Literary content: Article/Research & 3.8 & Literary content: Entry & 2.5 \\
\hline $\begin{array}{l}\text { Author identity: Academic } \\
\text { Professional }\end{array}$ & 4.0 & Author identity: Unknown & 1.0 \\
\hline Editorial process: Peer-Reviewed & 4.0 & $\begin{array}{l}\text { Editorial process: Collaborative } \\
\text { Editing }\end{array}$ & 2.5 \\
\hline $\begin{array}{l}\text { Publication purpose: Higher } \\
\text { Education }\end{array}$ & 4.0 & Publication purpose: Nonprofit & 3.3 \\
\hline Total score & 19.8 & Total score & 11.6 \\
\hline
\end{tabular}




\section{TABLE 5}

\section{Means of Agreement between Coders}

\begin{tabular}{|l|c|c|}
\hline Facet & Matches & \% Agreement \\
\hline Information Format & $6 / 9$ & 0.67 \\
\hline Literary Content & $8 / 9$ & 0.89 \\
\hline Author Identity & $9 / 9$ & 1.00 \\
\hline Editorial Process & $7 / 9$ & 0.78 \\
\hline Publication Purpose & $6 / 9$ & 0.67 \\
\hline Overall & $7.2 / 9$ & 0.80 \\
\hline
\end{tabular}

their research paper. Out of the entire class, 30 students played the game. The 70 remaining nonplayers formed the control group. All students were given an in-class introduction to the BiblioBouts game by the researchers, who also demonstrated gameplay. Students received bibliographic instruction from a visiting librarian, which consisted of a review of databases available through the university library and basic search techniques. This session focused only on introducing students to scholarly resources and query formulation. The librarian was not asked to tailor the instruction session to include evaluation strategies, because the game's Tagging \& Rating bout introduced students to an evaluation strategy and gave them handson practice evaluating sources using the strategy.

Final papers from both players and nonplayers were collected and anonymized. Bibliographies were extracted from the papers, and anonymous codenames were applied. Two independent coders (master's degree students in the School of Information) were then hired and given three sample student bibliographies to code. After an initial round of coding, results were compared and discussed to reach a consensus on the criteria to be used in coding. Differences of judgment were discussed and resolved, and agreement was reached on how the sample sources were to be coded.

The researchers randomly chose 30 bibliographies were from the entire pool of the class, with 15 chosen from students who played BiblioBouts (treatment group) and 15 from students who did not play (control group). These anonymized bibliographies were distributed equally to the two coders, who then applied the taxonomy and scoring system to the citations in each bibliography. For electronic sources, the coders checked the original URL to verify the source and code it. In some cases, facets were unidentifiable due to broken or incorrect URLs or lack of information on the site. In

\begin{tabular}{|l|c|c|c|c|}
\hline \multicolumn{5}{|c|}{ TABLE 6 } \\
Information Format Frequencies \\
\hline & Total & $\%$ & Total & $\%$ \\
\hline Blog & 33 & 25.8 & 10 & 10.2 \\
\hline Promotional Material & 18 & 14.1 & 12 & 12.2 \\
\hline Public Sharing Site & 1 & 0.8 & 1 & 1.0 \\
\hline Policy Statement & 1 & 0.8 & 0 & 0.0 \\
\hline Consumer Magazine & 7 & 5.5 & 7 & 7.1 \\
\hline Consumer Newspaper & 11 & 8.6 & 17 & 17.3 \\
\hline News Story & 6 & 4.7 & 7 & 7.1 \\
\hline Course Material & 3 & 2.3 & 1 & 1.0 \\
\hline Trade Newspaper & 6 & 4.7 & 2 & 2.0 \\
\hline Institutional Repository & 2 & 1.6 & 1 & 1.0 \\
\hline Trade Magazine & 10 & 7.8 & 14 & 14.3 \\
\hline Database & 4 & 3.1 & 3 & 3.1 \\
\hline Digital Repository & 1 & 0.8 & 1 & 1.0 \\
\hline Report & 10 & 7.8 & 5 & 5.1 \\
\hline Conference Proceedings & 2 & 1.6 & 3 & 3.1 \\
\hline Monograph & 6 & 4.7 & 10 & 10.2 \\
\hline Monographic Serial & 1 & 0.8 & 1 & 1.0 \\
\hline Scholarly Journal & 6 & 4.7 & 3 & 3.1 \\
\hline Total & 128 & 100 & 98 & 100 \\
\hline & & & & \\
\hline & 11.0 \\
\hline
\end{tabular}




\begin{tabular}{|l|c|c|c|c|}
\hline \multicolumn{5}{|c|}{ TABLE 7 } \\
\hline & \multicolumn{2}{c|}{ Players } & \multicolumn{2}{c|}{ Nonplayers } \\
\hline & Total & \% & Total & \% \\
\hline Posting & 27 & 21.1 & 2 & 2.1 \\
\hline Article/Essay & 24 & 18.8 & 12 & 12.8 \\
\hline Article/News & 18 & 14.1 & 26 & 27.7 \\
\hline $\begin{array}{l}\text { Public Relations/ } \\
\text { Promotional }\end{array}$ & 16 & 12.5 & 11 & 11.7 \\
\hline Article/Synthesis & 8 & 6.3 & 7 & 7.4 \\
\hline Article/Research & 7 & 5.5 & 5 & 5.3 \\
\hline Review & 6 & 4.7 & 4 & 4.3 \\
\hline Class Reading & 4 & 3.1 & 1 & 1.1 \\
\hline Treatise & 4 & 3.1 & 10 & 10.6 \\
\hline FAQ & 3 & 2.3 & 2 & 2.1 \\
\hline Column & 3 & 2.3 & 2 & 2.1 \\
\hline Editorial & 3 & 2.3 & 3 & 3.2 \\
\hline Entry & 2 & 1.6 & 7 & 7.4 \\
\hline Thesis & 2 & 1.6 & 0 & 0.0 \\
\hline Working Paper & 1 & 0.8 & 2 & 2.1 \\
\hline Total & 128 & 100 & 94 & 100 \\
\hline
\end{tabular}

The resulting overall mean of agreement was 0.80 , or 80 percent agreement between the raters. Given the large number of possible codes for each facet, the researchers felt confident in the overall level of agreement between the coders.

\section{Findings}

The frequency of use for each subtype within a facet was counted and the percentage of use by both players and nonplayers was calculated. This analysis revealed which were the most and least used facet subtypes in the coded citations. Results for each of the five facets by players and nonplayers are presented in tables 6 through 10.

Table 6 shows that the mostused Information Format for players was Blog $(25.8 \%)$, while for nonplayers the most-used format was Consumer Newspaper $(17.7 \%)$. In contrast, Blogs were used by only 10.4 percent

these cases, the facet was coded as a zero. When the facets were coded, the coders produced total scores for each individual citation as well as overall combined scores for each bibliography.

Applying inter-rater reliability analysis to this coding is difficult due to the small number of raters and the larger number of possible categories, which are nominal and independent of each other. Cohen's kappa statistics would not account for the margin of variance in the coding. Instead, a sample bibliography coded by both coders was analyzed for consistency of coding. This sample bibliography contained nine citations, and the codes were compared for each of the taxonomy facets. Total percentage of agreement (mean) was calculated. See table 5.

\begin{tabular}{|l|c|c|c|c|}
\hline \multicolumn{5}{|c|}{ TABLE 8 } \\
Author Identity Frequencies \\
\hline & \multicolumn{2}{|c|}{ Players } & \multicolumn{2}{c|}{ Nonplayers } \\
\hline & Total & $\%$ & Total & $\%$ \\
\hline Applied professional & 63 & 49.2 & 59 & 56.7 \\
\hline Corporate authorship & 21 & 16.4 & 15 & 14.4 \\
\hline Academic professional & 19 & 14.8 & 14 & 13.5 \\
\hline Professional-amateur & 17 & 13.3 & 5 & 4.8 \\
\hline Unknown authorship & 8 & 6.3 & 11 & 10.6 \\
\hline Total & 128 & 100 & 104 & 100 \\
\hline
\end{tabular}
of nonplayers, while Consumer Newspapers were used by only 8.6 percent of players. Overall, Scholarly Journals were used by only 4.7 percent of players and 3.1 percent of nonplayers.

Table 7 shows that players used Postings as the most frequent Literary Content $(21.8 \%)$, which follows from the use of Blogs as most-used Information Format. 


\begin{tabular}{|l|c|c|c|c|}
\hline \multicolumn{5}{|c|}{ TABLE 9 } \\
Editorial Process Frequencies \\
\hline & \multicolumn{2}{|c|}{ Players } & \multicolumn{2}{c|}{ Nonplayers } \\
\hline & Total & $\%$ & Total & $\%$ \\
\hline $\begin{array}{l}\text { Editor and editorial } \\
\text { staff }\end{array}$ & 72 & 56.3 & 75 & 72.1 \\
\hline Self-published & 20 & 15.6 & 5 & 4.8 \\
\hline Peer-reviewed & 13 & 10.2 & 9 & 8.7 \\
\hline Vanity press & 11 & 8.6 & 3 & 2.9 \\
\hline $\begin{array}{l}\text { Moderated } \\
\text { submissions }\end{array}$ & 11 & 8.6 & 10 & 9.6 \\
\hline Collaborative editing & 1 & 0.8 & 2 & 1.9 \\
\hline Total & 128 & 100 & 104 & 100 \\
\hline
\end{tabular}

Staff, which follows from the reliance on blogs and consumer newspapers. While this is certainly true of newspapers but much less certain with blogs, the blogs used were checked by the coders for evidence of an editorial process to review the content of postings. Peerreviewed sources were the third choice for both players $(10.7 \%)$ and nonplayers $(9.4 \%)$.

Table 10 shows that both players $(76.6 \%)$ and nonplayers (90.6\%) relied primarily on Commercial publications for their citations. While Higher Education

Likewise, following their use of consumer newspapers as the most-used Information Format, nonplayers used Article/News as the most frequent Literary Content $(27.1 \%)$. Higher-quality sources such as Article/Research or Treatise were used by only a small percentage of participants $(3 \%-6 \%$ of players and $5 \%-10 \%$ of nonplayers).

Table 8 shows that the most-used Author Identity for both players (52.1\%) and nonplayers (61.5\%) was Applied Professional, which follows from the reliance on blogs and consumer newspapers as Information Formats. Although the authors of blogs in particular may not always be considered professionals, in the case of technology blogs the credentials of the authors often relate to the topic being discussed and give the author somewhat more credibility than a layman. When available, the biographical description of blog authors was checked by the coders for evidence of professional experience. Sources with Academic Professional as the Author Identity were used by 15.7 percent of players and 14.6 percent of nonplayers.

Table 9 shows that the mostused Editorial Process for both players $(59.5 \%)$ and nonplayers (78.1\%) was Editor and Editorial was the second most-used facet for both players (15.3\%) and nonplayers (14.6\%), it still lags far behind the other categories.

Some categories in the taxonomy were not used in any of the coded bibliographies. For Facet 1: Information Format, neither players nor nonplayers used Directory, Encyclopedia, Informational Video, or Trade Journal. In addition, nonplayers did not use Policy Statement. For Facet 2: Literary Content, neither used Manual, Biography, Preprint/Postprint, Article/ Lit Review, or Dissertation. In addition, nonplayers did not use Thesis. For Facet 3: Author Identity, neither players nor nonplayers used Layman. All categories were used for Facet 4: Editorial Process. For Facet 5: Publication Purpose, nonplayers did not use the Government category.

\begin{tabular}{|l|c|c|c|c|}
\hline \multicolumn{5}{|c|}{ TABLE 10 } \\
Publication Purpose Frequencies \\
\hline & \multicolumn{2}{|c|}{ Players } & \multicolumn{2}{c|}{ Nonplayers } \\
\hline & Total & $\%$ & Total & $\%$ \\
\hline Commercial & 95 & 74.8 & 87 & 80.6 \\
\hline Higher education & 19 & 15.0 & 14 & 13.0 \\
\hline Personal & 5 & 3.9 & 1 & 0.9 \\
\hline Nonprofit & 4 & 3.1 & 1 & 0.9 \\
\hline K-12 education & 3 & 2.4 & 5 & 4.6 \\
\hline Government & 1 & 0.8 & 0 & 0.0 \\
\hline Total & 127 & 100 & 108 & 100 \\
\hline
\end{tabular}


Once the individual citation coding was completed, the researchers analyzed the usage of scholarly databases by players and nonplayers. Bibliographic citations were checked for reference to a database used to find the source; these were indicated mainly by the inclusion of a URL in the citation or the mention of a database in the citation without a URL (that is, "retrieved from ProQuest"). Specific databases owned by larger services such as Gale and ProQuest were counted under the larger umbrella.

Table 11 shows that players used more scholarly databases (31) than nonplayers (25) and that both groups relied on ProQuest in particular for the majority of the identified citations ( 33 out of 56 , or $59 \%$ ). This suggests that awareness of the ProQuest database is fairly high among these undergraduates, but familiarity with other databases may be low.

Usage of refereed journals in the citations was also analyzed. Where citations gave clear citations to journals, Ulrich's Periodical Directory was consulted to establish if the journal was categorized as

\begin{tabular}{|l|c|c|}
\hline \multicolumn{3}{|c|}{ TABLE 11 } \\
\hline \multicolumn{2}{|c|}{ Databases Used } \\
\hline $\begin{array}{l}\text { Databases (based on } \\
\text { URLs) }\end{array}$ & Players & Nonplayers \\
\hline $\begin{array}{l}\text { Business \& Company } \\
\text { Resource Center }\end{array}$ & 0 & 2 \\
\hline EBSCO & 1 & 0 \\
\hline $\begin{array}{l}\text { Gale (including } \\
\text { Academic OneFile) }\end{array}$ & 0 & 2 \\
\hline Gartner & 3 & 0 \\
\hline General Business File & 0 & 1 \\
\hline LexisNexis Academic & 0 & 6 \\
\hline OCLC First Search & 1 & 0 \\
\hline $\begin{array}{l}\text { ProQuest (including } \\
\text { ABI/Inform) }\end{array}$ & 21 & 12 \\
\hline Sage & 0 & 1 \\
\hline ScienceDirect & 1 & 0 \\
\hline SpringerLink & 4 & 1 \\
\hline Total & 31 & 25 \\
\hline
\end{tabular}

"refereed." Seven articles from refereed journals were identified in the sample bibliographies, with a total of six citations from players and four citations from nonplayers.

Table 12 shows that two refereed journals were cited by both players and nonplayers: Decision Support Systems and Journal of Cases on Information Technology. Both players used ProQuest to find the Decision Support Systems article, while one player used ProQuest and one player used Gale to find the Journal of Cases on Information Technology article. For both players and nonplayers, one bibliography contained two scholarly citations, suggesting that the particular student may have been a more experienced researcher.

Finally, the overall results for players and nonplayers were analyzed. Average number of citations per bibliography, average citation score, and average bibliography score were compared. The overall citation score is the average of all citations in all the coded bibliographies, and the overall bibliography score is the average of the total bibliography scores. These averages present a generalized picture of the final bibliographies of both players and nonplayers.

Table 13 shows that, on average, player bibliographies contained more citations (8.6) than nonplayer bibliographies (7.2). This may suggest that players of BiblioBouts are exposed to more sources and thus include more citations in their bibliographies. The average citation scores were very close for both groups, with nonplayers scoring slightly higher (13.7) than players (13.5). Why the nonplayer citation score is higher is not clear, as both players and nonplayers relied primarily on nonscholarly online sources. As shown previously in table 6, players most frequently used Blogs and Promotional Materials, while nonplayers most frequently used Consumer Newspapers and Trade Magazines. This may be re- 


\begin{tabular}{|l|c|c|}
\hline \multicolumn{3}{|c|}{ TABLE 12 } \\
Citations from Refereed Journals \\
\hline Journal & Players & Nonplayers \\
\hline Decision Support Systems & 1 & 1 \\
\hline European Management Journal & 2 & 0 \\
\hline International Journal of Advertising & 1 & 0 \\
\hline Journal of Adolescent Research & 0 & 1 \\
\hline Journal of Cases on Information Technology & 1 & 0 \\
\hline Journal of Information Systems Education & 1 & 1 \\
\hline $\begin{array}{l}\text { J. of Theoretical and Applied Electronic } \\
\text { Commerce Research }\end{array}$ & 0 & 4 \\
\hline Total & 6 & 1 \\
\hline
\end{tabular}

lated to the assignment topic, "Business Models for Web 2.0 Social Networking Sites \& Platforms," which lent itself to a reliance on up-to-date commercial sources. The higher average bibliography score for players (110.1) vs. nonplayers (95.5) reflects the higher average number of citations per bibliography, as well as the fact that players used more scholarly databases and cited slightly more refereed journals than nonplayers.

\section{Discussion}

In this study, a faceted taxonomy for rating student bibliographies was developed to evaluate the overall quality of student work as exhibited in the research bibliography and to apply a standardized coding and rating system to quantify the results. The goal of this taxonomy was to operationalize "quality" in a manner relevant to the variety of online resources used by today's students. The use of a faceted classification allowed for a fine-grained analysis of varying sources with varying levels of quality. The results of this study suggest that this faceted taxonomy

\begin{tabular}{|l|c|c|}
\hline \multicolumn{3}{|c|}{ TABLE 13 } \\
Results for Players and Nonplayers \\
\hline Average & Players & Nonplayers \\
\hline Citations per bibliography & 8.6 & 7.2 \\
\hline Citation score & 13.5 & 13.7 \\
\hline Bibliography score & 110.1 & 95.5 \\
\hline
\end{tabular}

provides a standardized assessment tool that is flexible enough to encompass the variety of online sources available to students. The proposed taxonomy is adaptable and can be enhanced to meet the changing nature of online information sources. Additional categories can be added to any facet without changing the overall system. The scoring may be modified by instructors if they wish. The faceted classification system is flexible enough to be modified in many small ways without losing its overall integrity.

Analysis of the sample bibliographies showed that most students did not use scholarly resources for the citations in their bibliographies. In part, this may be attributable to the assignment topic ("Business Models for Web 2.0 Social Networking Sites \& Platforms"), which lent itself to online sources that might reasonably have more up-to-date information. Since the paper assignment did not require the students to cite scholarly sources, they were free to select whichever sources they wanted. Relevant scholarly sources did exist, as noted by the use of the refereed journals Decision Support Systems and Journal of Cases on Information Technology. Many more scholarly sources were donated to the BiblioBouts group collection than were included in the sample bibliographies analyzed in this study.

Overall, a small percentage of sources (21\%) in the coded bibliog- 
raphies came from the BiblioBouts game, meaning that most students opted for sources they found on their own outside the game. The reasons for this are not clear. There were some technical difficulties during the pilot test that may have discouraged players from participating fully and prompted them to complete to their papers on their own. Students may also have relied on force of habit in finding their own sources rather than putting time and effort into the game. If players had used a higher percentage of sources from the game, which were rated and evaluated by other players to establish a consensus assessment of quality, it is likely that the average citation and overall bibliography scores would have been higher.

Results of the coding and scoring demonstrated that game players used more scholarly databases, cited more refereed journals, included more citations per bibliography, and achieved higher overall bibliography scores than nonplayers. While the percentage differences are not large, these initial findings suggest that the game had a positive impact on players' research behavior. Thus, the researchers feel that the BiblioBouts game holds out the promise of directly integrating information literacy skills into the classroom setting, so that students see the utility of the skills and can apply them to actual assignments. Rather than relying on a segregated, formal instruction session on information literacy, which may seem abstract to students and not directly related to their coursework, skills are learned during game play in a useful and practical context related directly to their class requirements.

These findings have provided very useful data for the project team and have driven the improvements being made to the next version of the game. Among these is a much greater focus on directing students to use online scholarly databases, through the addition of in-game recommendations from the class instructor as well as repeated reinforcement through displaying the databases used by other players who have made donations. In addition, the improved game will provide suggestions for keywords to be used in searching and display keywords attached to documents other players have donated. It is hoped that, through the implementation of these refinements, the BiblioBouts research team will see continued improvement in the quality of bibliographies of students who play the game.

\section{Possible Limitations}

This pilot test is by definition preliminary, and these initial results require further verification. The proposed taxonomy was only applied in one class, to a small sample of student bibliographies, which limits the generalizability of the results. Other limitations include the fact that only three faculty members were involved in creating the scoring values. A wider sample of faculty may produce different scores. Overall, the researchers feel that these initial results are still useful and suggest that online gaming to teach information literacy skills may be useful to librarians, information literacy instructors, and faculty who assign undergraduate research papers.

\section{Future Research}

There are several directions for future research involving the faceted taxonomy, now that it has been successfully deployed. As the BiblioBouts game is refined and its ease of use improves, we expect to see greater active participation by both students and instructors, which we expect will improve results further. When instructors are actively involved in the game, their donations of high-quality sources will act as models for their students. The impact of this increased participation can be measured by using the taxonomy to assess all donated sources in the game, not just a sample. This will also allow the researchers to evaluate the differences in quality between those sources donated, but not chosen for the final bibliographies, with the chosen sources, to assess the overall improvement in quality as a result of the evaluation strategies introduced during the game. 


\section{Notes}

1. Colleen Boff and Kristin Johnson, "The Library and First-Year Experience Courses: A Nationwide Study," Reference Services Review 30, no. 4 (2002): 277-87.

2. Andrew Walsh, "Information Literacy Assessment: Where Do We Start?" Journal of Librarianship and Information Science 41 (2009): 19.

3. Karen Hovde, "Check The Citation: Library Instruction and Student Paper Bibliographies," Research Strategies 17, no. 1 (2000): 3-9.

4. Tefko Saracevic, "Relevance: A Review of the Literature and a Framework for Thinking on the Notion in Information Science, Part III: Behavior and Effects of Relevance," Journal of the American Society for Information Science and Technology 58, no. 13 (2007): 1915-33.

5. Anne Middleton, "An Attempt to Quantify the Quality of Student Bibliographies," Performance Measurement and Metrics 6, no. 1 (2005): 7-18.

6. Thomas Kirk, "A Comparison of Two Methods of Library Instruction for Students in Introductory Biology," College \& Research Libraries 32, no. 6 (1971): 465-74.

7. Amy Dykeman and Barbara King, "Term Paper Analysis: A Proposal for Evaluating Bibliographic Instruction," Research Strategies 1, no. 1 (1983): 14-21.

8. Bonnie Gratch, "Toward a Methodology for Evaluating Research Paper Bibliographies," Research Strategies 3, no. 4 (1985): 170-77.

9. David F. Kohl and Lizabeth A. Wilson, "Effectiveness of Course-Integrated Bibliographic Instruction in Improving Coursework," RQ 27, no. 2 (1986): 206-11.

10. Virginia E. Young and Linda G. Ackerson, "Evaluation of Student Research Paper Bibliographies: Refining Evaluation Criteria," Research Strategies 13, no. 2 (1995): 80-93.

11. Stacey Knight-Davis and Jan S. Sung, "Analysis of Citations in Undergraduate Papers," College \& Research Libraries 69, no. 5 (2008): 447-58.

12. Reba Leiding, "Using Citation Checking of Undergraduate Honors Thesis Bibliographies to Evaluate Library Collections," College \& Research Libraries 66, no. 5 (2005): 417-29.

13. Laurel A. Haycock, "Citation Analysis of Education Dissertations for Collection Development," Library Resources and Technical Services 48 no. 2 (2004): 102-06.

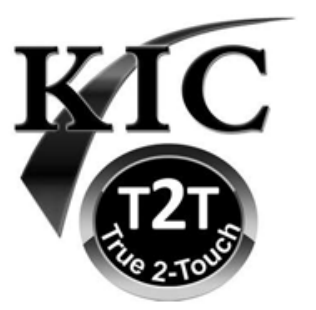

\section{Knowledge Imaging Centers}

\section{Self-Serve Systems to Mine Your Print Collections}

Students entering college expect digital. Most of your scholarly assets are in print form. That's why speed and throughput are so important when choosing self-serve digitizing systems. And that's why KIC is available to half of the students at the top 100 academic institutions.

\section{Multiple Unit Purchases Start at \$ 3,999}
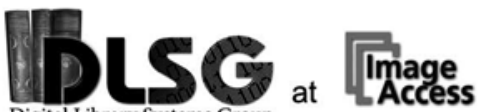

800.378.5432 | www.imageaccess.com | www.dlsg.net
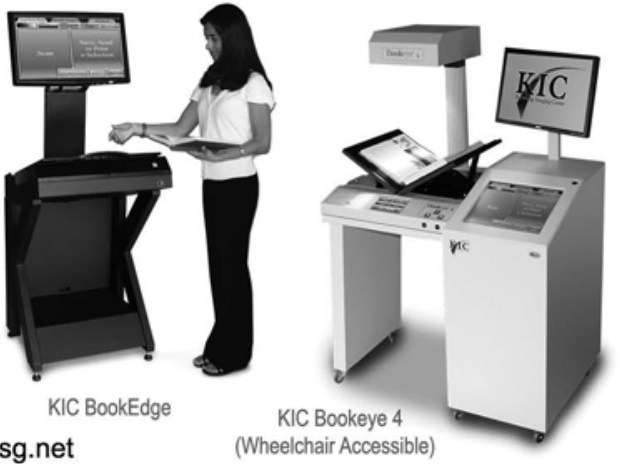
14. Robin N. Sinn, "A Local Citation Analysis of Mathematical and Statistical Dissertations," Science \& Technology Libraries 25, no. 4 (2005): 25-37.

15. Daniel P. Coffey, "ADiscipline's Composition: A Citation Analysis of Composition Studies," The Journal of Academic Librarianship 32, no. 2 (2006): 155-65.

16. Pali U. Kuruppu and Debra C. Moore, "Information Use by PhD Students in Agriculture and Biology: A Dissertation Citation Analysis," portal: Libraries and the Academy 8, no. 4 (2008): 387-405.

17. Núria Vallmitjana and L.G. Sabaté, "Citation Analysis of Ph.D. Dissertation References as a Tool for Collection Management in an Academic Chemistry Library," College \& Research Libraries 69, no. 1 (2008): 72-82.

18. C. Keith Waugh and Margie Ruppel, "Citation Analysis of Dissertation, Thesis, and Research Paper References in Workforce Education and Development," The Journal of Academic Librarianship 30, no. 4 (July 2004): 276-84.

19. Hovde, "Check the Citation."

20. Debbie Malone and Carol Videon, "Assessing Undergraduate Use of Electronic Resources: A Quantitative Analysis of Works Cited." Research Strategies 15, no. 3 (1997): 151-58.

21. Philip M. Davis, "The Effect of the Web on Undergraduate Citation Behavior: A 2000 Update," College \& Research Libraries 63, no. 1 (2002): 53-60.

22. Maria Elizabeth Clarke and Charles Oppenheim, "Citation Behaviour of Information Science Students II: Postgraduate Students," Education for Information 24, no. 1 (2006): 1-30.

23. Lara Ursin, Elizabeth Blakesley Lindsay, and Corey M. Johnson, "Assessing Library Instruction in the Freshman Seminar: A Citation Analysis Study," Reference Services Review 32, no. 3 (2004): 284-92.

24. Andrew Robinson and Karen Schlegel, "Student Bibliographies Improve When Professors Provide Enforceable Guidelines for Citations," portal: Libraries and the Academy 4, no. 2 (2004): 275-90.

25. Mark Emmons and Wanda Martin, "Engaging Conversation: Evaluating the Contribution of Library Instruction to the Quality of Student Research," College and Research Libraries 63, no. 6 (2002): 545-60.

26. Rui Wang, "The Lasting Impact of a Library Credit Course," portal: Libraries and the Academy 6, no. 1 (2006): 79-92.

27. Jake Carlson, "An Examination of Undergraduate Student Citation Behavior," The Journal of Academic Librarianship 32, no. 1 (2006): 14-22.

28. Holly Heller-Ross, "Assessing Outcomes with Nursing Research Assignments and Citation Analysis Of Student Bibliographies," Reference Librarian 77 (2002): 121-40.

29. Fei Yu, Jan Sullivan, and Leith Woodall, "What Can Students' Bibliographies Tell Us? Evidence Based Information Skills Teaching for Engineering Students," Evidence Based Library and Information Practice 1, no. 2 (2006). Available online at http://ejournals.library.ualberta.ca/index. php/EBLIP/article/view/8 [accessed 30 November 2011].

30. Johanna Tuñón and Bruce Brydges, "A Study on Using Rubrics and Citation Analysis to Measure the Quality of Doctoral Dissertation Reference Lists from Traditional and Nontraditional Institutions," Journal of Library Administration 45, no. 3 (2006): 459-81.

31. Gloriana St. Clair and Rose Mary Magrill, "Incomplete Citations in Undergraduate Term Papers from Four Campuses. RQ 30, no. 1 (1990): 75-81.

32. Knight-Davis and Sung, "Analysis of Citations in Undergraduate Papers."

33. Robinson and Schlegel, "Student Bibliographies Improve When Professors Provide Enforceable Guidelines for Citations."

34. Lorrie A. Knight, “Using Rubrics to Assess Information Literacy," Reference Services Review 34, no. 1 (2006): 43-55.

35. Tuñón and Brydges, "A Study on Using Rubrics and Citation Analysis," 464.

36. Dykeman and King, "Term Paper Analysis."

37. Casey M. Long and Milind M. Shrikhande, "Improving Information-seeking Behavior Among Business Majors," Research Strategies 20, no. 4 (2005): 357-69.

38. Ada Emmett and Judith Emde, "Assessing Information Literacy Skills Using the ACRL Standards as a Guide," Reference Services Review 35, no. 2 (2007): 218.

39. Philip M. Davis and Suzanne A. Cohen, "The Effect of the Web on Undergraduate Citation Behavior 1996-1999," Journal of the American Society for Information Science and Technology 52, no. 4 (2001): 309-14.

40. Penny M. Beile, David N. Boote, and Elizabeth K. Killingsworth, "Characteristics of Education Doctoral Dissertation References: An Inter-Institutional Analysis of Review of Literature Citations" (paper presented at the annual meeting of the American Educational Research Association, Chicago, Illinois, April 21-25, 2003).

41. N.N. Edzan, "Analysing the References of Final Year Project Reports," Journal of Educational 
Media E Library Sciences 46, no. 2 (2008): 211-31.

42. Tuñón and Brydges, "A Study on Using Rubrics and Citation Analysis."

43. Middleton, "An Attempt to Quantify the Quality of Student Bibliographies."

44. Heller-Ross, "Assessing Outcomes with Nursing Research Assignments."

45. Lisa Janicke Hinchliffe, Chrstine Kubiak, Stephen Hunt, and Cheri Simonds, "What Students Really Cite: Findings from a Content Analysis of First-Year Student Bibliographies," in Integrating Information Literacy into the College Experience, Papers Presented at the Thirtieth National LOEX Library Instruction Conference, May 10-11, 2002, eds. Julia K. Nims, Randal Baier, Rita Bullard, Eric Owen (Ann Arbor, MI: Pierian Press, 2003): 69-74.

46. Charles Oppenheim and Richard Smith, "Student Citation Practices in an Information Science Department," Education for Information 19, no. 4 (2001): 299-323.

47. Young and Ackerson, "Evaluation of Student Research Paper Bibliographies."

48. Gratch, "Toward a Methodology for Evaluating Research Paper Bibliographies."

49. Kohl and Wilson, "Effectiveness of Course-Integrated Bibliographic Instruction."

50. Malone and Videon, "Assessing Undergraduate Use of Electronic Resources."

51. Hinchcliffe et al., "What Students Really Cite."

52. Beth A. Mohler, "Citation Analysis as an Assessment Tool," Science \& Technology Libraries 25, no. 4 (2005): 57-64.

53. Wang, "The Lasting Impact of a Library Credit Course."

54. Emmett and Emde, "Assessing Information Literacy Skills," 214.

55. Colleen Cool and Nicholas J. Belkin, "A Classification of Interactions with Information," in Emerging Frameworks and Methods, Proceedings of the Fourth International Conference on Conceptions of Library and Information Science (COLIS4) 2002, eds. Harry Bruce, Ray Fidel, Peter Ingwersen, and Pertti Vakkari (Greenwood Village, CO: Libraries Unlimited, 2002): pp. 1-15.

56. Kevin Crowston and B.H. Kwasnik, "A Framework for Creating a Faceted Classification for Genres: Addressing Issues of Multidimensionality," in Proceedings of the 37th Hawaii International Conference on System Sciences (HICSS-37), Big Island, HI (Los Alamitos, CA: IEEE Press, 2004): 5-7.

\section{Use these Archive-Quality Scanners to}

Create digital archives $\cdot$ Print books on demand $\cdot$ Create course curriculum materials - Create 3-D digital collections for the Web \& 3rd party content managers

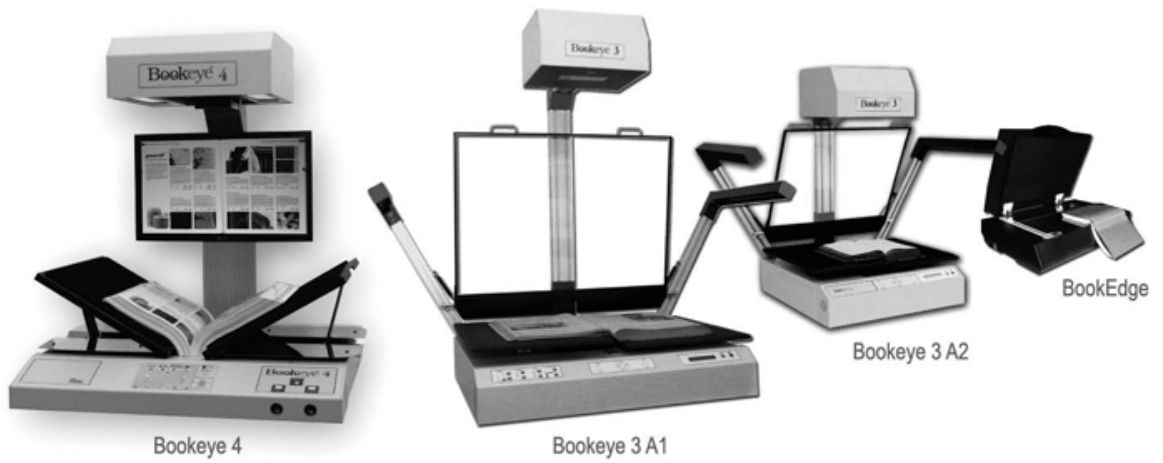

Opus runs the best archive/preservation-quality scanners available today and manages projects ranging from scanning a few pages to creating complete digital libraries using sophisticated, multi-stage workflow systems.

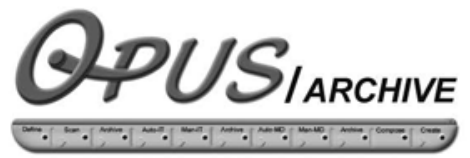

Digital archiving without the complexity

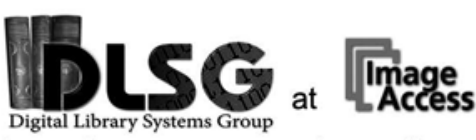

800.378.5432 | www.imageaccess.com | www.dlsg.net 